\title{
Digital Radiography Using Digital Detector Arrays Fulfills Critical Applications for Offshore Pipelines
}

\author{
Edson Vasques Moreira, ${ }^{1,2}$ José Maurício Barbosa Rabello, ${ }^{3}$ Marcelo dos Santos Pereira, ${ }^{4}$ \\ Ricardo Tadeu Lopes, ${ }^{5}$ and Uwe Zscherpel ${ }^{6}$ \\ ${ }^{1}$ Nondestructive Testing Laboratory of TenarisConfab, 475 Av. Dr. Gastão Vidigal Neto, Pindamonhangaba, 12414-900, SP, Brazil \\ ${ }^{2}$ Universidade Estadual Paulista (UNESP)-FEG, 333 Av. Doutor Ariberto Pereira da Cunha, Guaratinguetá, 12516-410, SP, Brazil \\ ${ }^{3}$ Petrobras/Engenharia/SL/SEQUI/CI, Km 143 Rodovia Presidente Dutra, São José dos Campos, 12220-840, SP, Brazil \\ ${ }^{4}$ Department of Materials and Technology, UNESP, FEG, 333 Av. Doutor Ariberto Pereira da Cunha, \\ Guaratinguetá, 12516-410, SP, Brazil \\ ${ }^{5}$ Nuclear Instrumentation Laboratory, COPPE, Universidade Federa do Rio de Janeiro, Rio de Janeiro, Brazil \\ ${ }^{6}$ BAM, Federal Institute for Materials Research and Testing, Radiological Methods, 87 Unter den Eichen, 12205, Berlin, Germany
}

Correspondence should be addressed to Edson Vasques Moreira, edsonvasques@uol.com.br

Received 11 November 2009; Revised 10 February 2010; Accepted 27 April 2010

Academic Editor: João Manuel R. S. Tavares

Copyright () 2010 Edson Vasques Moreira et al. This is an open access article distributed under the Creative Commons Attribution License, which permits unrestricted use, distribution, and reproduction in any medium, provided the original work is properly cited.

Digital radiography in the inspection of welded pipes to be installed under deep water offshore gas and oil pipelines, like a presalt in Brazil, in the paper has been investigated. The aim is to use digital radiography for nondestructive testing of welds as it is already in use in the medical, aerospace, security, automotive, and petrochemical sectors. Among the current options, the DDA (Digital Detector Array) is considered as one of the best solutions to replace industrial films, as well as to increase the sensitivity to reduce the inspection cycle time. This paper shows the results of this new technique, comparing it to radiography with industrial films systems. In this paper, 20 test specimens of longitudinal welded pipe joints, specially prepared with artificial defects like cracks, lack of fusion, lack of penetration, and porosities and slag inclusions with varying dimensions and in 06 different base metal wall thicknesses, were tested and a comparison of the techniques was made. These experiments verified the purposed rules for parameter definitions and selections to control the required digital radiographic image quality as described in the draft international standard ISO/DIS 10893-7. This draft is first standard establishing the parameters for digital radiography on weld seam of welded steel pipes for pressure purposes to be used on gas and oil pipelines.

\section{Introduction}

Industrial radiographic films have been utilized for many years in the quality control by NDT of a variety of products; however, the use of digital radiography has recently been implemented in several sectors, for example, the medical, aerospace, security, automotive and petrochemical sectors. In addition to the technological trend it has been demonstrated that digital radiography sometimes offers a series of benefits in terms of productivity, sensitivity, environmental aspects, image treatment tools, cost reduction, security, POF improvement [1], and so forth.

Among the current options, the digital detector array, DDA, Varian $2520 \mathrm{~V}, 127 \mu \mathrm{m}$, employed in this paper is considered one of the best solutions to use online in plants that produces pieces in series and for obtaining digital images in place of films and reducing the inspection cycle time thanks to its high degree of automation [2].

Therefore, the work reported here involved the testing and evaluation of results achieved with this new technique, comparing them with those obtained by conventional film radiography. In this paper, test specimens of longitudinal welded pipes by the submerged-arc welding, process, especially prepared with artificial defects of the most varied dimensions, were tested and a comparison was made of the sensitivity of the techniques employed.

After conducting several experiments to evaluate the highest contrast sensitivity using wire-type Image Quality 
Indicator (IQI), Basic Spatial Resolution (BSR), and Signal Noise Ratio (SNR) normalized by the Basic Spatial Resolution and comparing artificial defects, the digital method showed better results and advantages compared with conventional film technique. These experiments were carried out to support the voting and the development of the first ISO document applicable to digital radiography using DDA for weld seam inspection on welded pipes for pressure, the ISO/DIS 10893-7 specification [3].

\section{Digital Radiography}

Digital radiography systems offer the possibility of obtaining images with much less strict exposure requirements than those of conventional film systems. Exposure imprecision normally leads to radiographs that are dark, light or show little contrast, which are easily improved and enhanced using digital techniques.

Some the advantages of digital radiographic systems include: image display, reduction of X-ray doses, image processing, automated acquisition, partially or completely automated evaluation, image storage, and the retrieval is significantly reduced.

The entire operation is simplified, from obtaining the image to the cycle time involved in obtaining, evaluating and storing each image with ensured traceability [4], as illustrated in Figure 2.

Different to industrial films, a fully integrated environment for digital radiographic images adds even other advantages [5] to these of the DDAs, for example: productivity and sensitivity are increased resulting in fast decisions using remote access, meetings, training, Level 3 supervision, process control monitoring, and so forth.

\section{Materials and Method}

For this investigation a Digital Detector Array, PaxScan $2520 \mathrm{~V}$ from Varian was used with a $25 \times 20 \mathrm{~cm}^{2}$ input screen of a scintillator DRZ Plus (GdO2S), and $127 \mu \mathrm{m}$ pixel size, resulting in a Basic Spatial Resolution (SRb) of $130 \mu \mathrm{m}$. The data transfer to the computer via GBit Ethernet interface allows an image transfer rate of 10 frames per second in full resolution. The software "Image 3500DD" from YXLON was used for data acquisition, image integration, DDA calibration and data storage [6].

The image evaluation was done using the BAM Software, "ISee!", see http://www.kb.bam.de/ic. Figure 3(a) shows an inside photo of the DDA and Figure 3(b) shows details of the DDA construction, which consists of a matrix of millions of light sensitive photo diodes direct into contact to the scintillator screen, not shown.

3.1. Materials Involved. The pipes are manufactured with laminated carbon steel plates, according to the requirements established by API 5L and ISO 3183 specifications $[7,8]$.

For high-strength pipes, microalloyed steels are produced with a high level of control of the fundamental parameters throughout the manufacturing process, comprising a specific set of steels whose chemical composition and other parameters are especially developed to attain high values of mechanical properties.

The samples of steel API 5L, grade X65 were manually welded by welding process SMAW (Shielded Metal Arc Welding). The manufacturing and selection of samples was done at TenarisConfab, they contain a huge number of introduced critical artificial welding flaws such as longitudinal and transversal cracks, lack of penetration, lack of side wall fusion, and porosities and slag inclusions.

3.2. Technique. The currently applied conventional technique using industrial films of class 1 , in accordance with ASTM 1815, was evaluated and compared with the digital technique using the described DDA. For these investigations a High Power X-ray tube Y.TU 225 D04: was used, with max. $225 \mathrm{kV}$ and a small focus $0.4 \mathrm{~mm}$ with $800 \mathrm{~W}$ and a large focus of $1 \mathrm{~mm}$ with max. $1.8 \mathrm{~kW}$ (certified according to EN 125432 ), anode angle $11^{\circ}$, and $4 \mathrm{~mm}$ inherent Aluminum filter at tube exit window [9].

The setup for digital radiography is shown in Figure 4 and the source to detector distance (SDD) and the object to detector distance (ODD) were varied to change the magnification factor (a max. of 1,2 was used) in accordance with the focal size used $(0,4$ or $1,0 \mathrm{~mm})$ and the wall thickness to be inspected.

The diaphragm at the tube port was adjusted that only the length to be inspectioned was exposed by X-rays to reduce the amount of scattered radiation

3.3. Compensation Principle. In accordance with ISO/DIS 10893-7 purpose it is possible to apply the compensation principle if duplex IQI required by the mentioned standard cannot be achieved by the used detector system. A visibility increase in the contrast IQI single wire can compensate too high unsharpness values. If ISO/DIS 10893-7 requires to show, that is, the duplex wire number D12 and the contrast sensitivity wire number 14 , W14, but they are not achieved at the same time for a specific detector setup, an increased contrast sensitivity W16 but a larger unsharpness D10 provides equal detection sensitivity (compensation principle) $[10,11]$.

The contrast sensitivity depends for DDA on the used integration time and X-ray tube setting used for acquisition of the radiographic images. An increased exposure time or dose of the DDA allows or increase the contrast sensitivity to values higher than reachable with industrial films $[3,10]$.

3.4. Magnification Technique. The pixel size of this DDA systems is large $(127 \mu \mathrm{m})$ compared with the small grain size in the film [9]. As a result the Basic Spatial Resolution is limited to $130 \mu \mathrm{m}$, which corresponds to the duplex wire D9.

This difficulty was circumvented by the following two possible approaches:

(1) increase the Signal to Noise Ratio (SNR) in the image for higher wire sensitivity to compensate the reduced duplex wire resolution, 


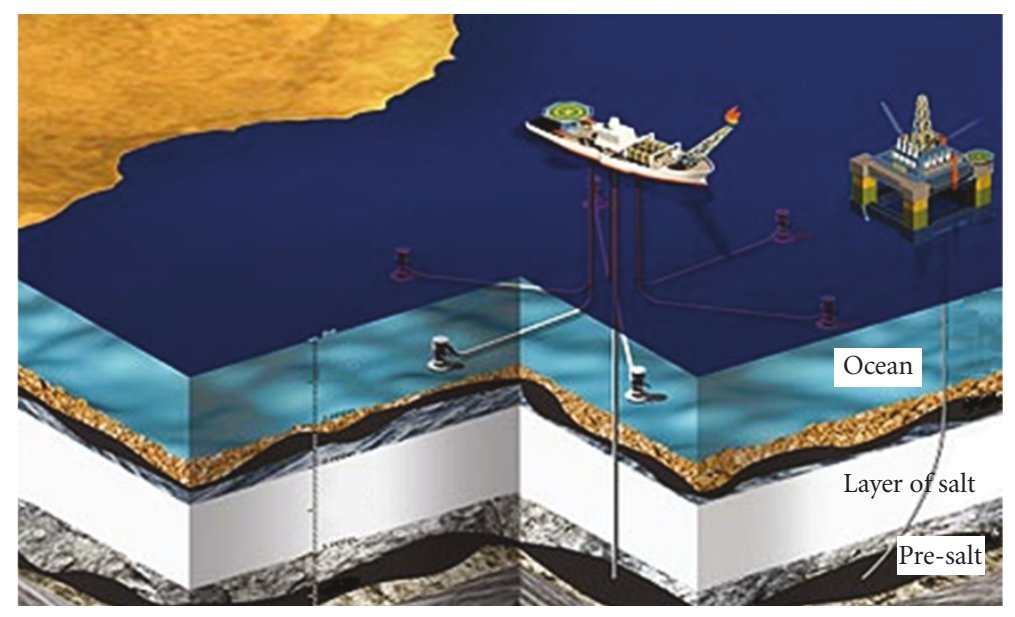

FIgure 1: Pipeline in deep water. Presalt in Brazil.

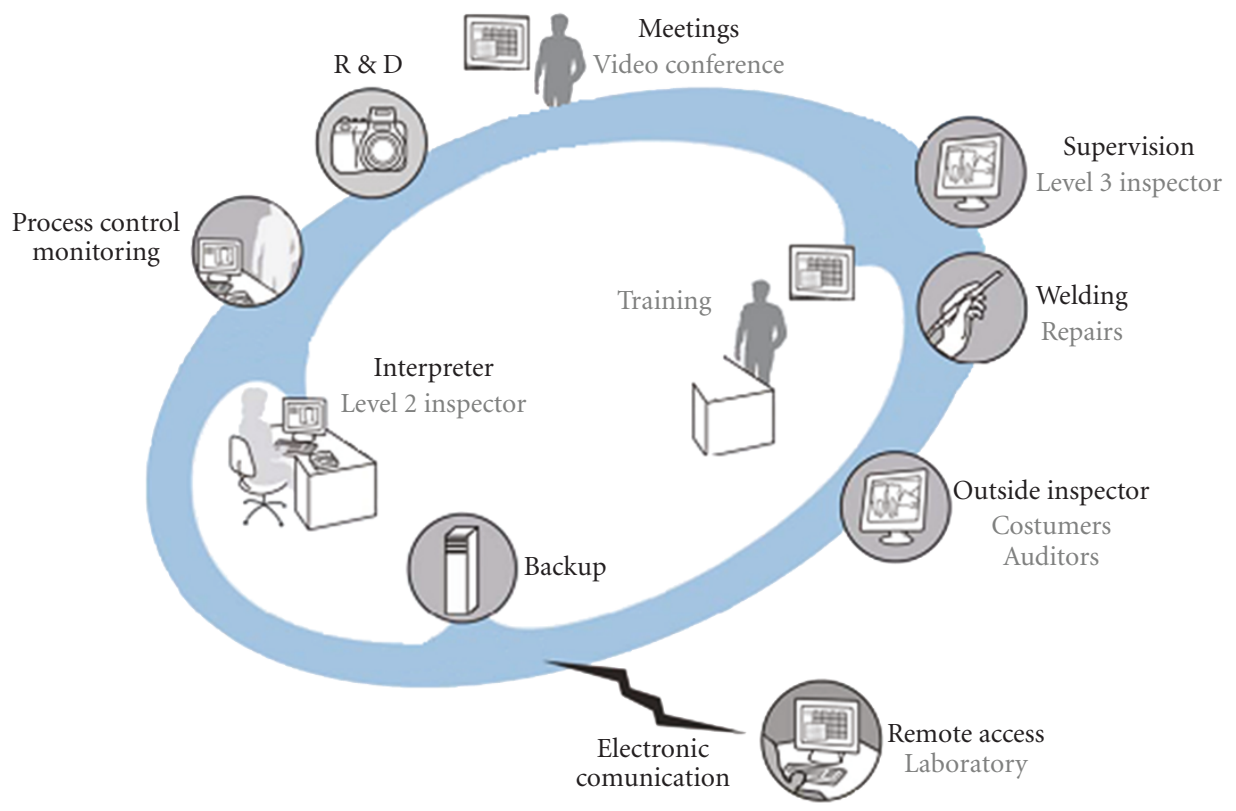

FIGURE 2: Full integrated environment for digital radiographic image [4].

(2) increase the X-Ray geometric magnification. In these experiments the magnifications were between 1.1 to 1.2 .

\section{Results}

The basic parameters for evaluation of the image quality are the following: the normalized Signal-to-Noise Ratio (SNRn) at base material, the Basic Spatial Resolution (SRb) and the Contrast Sensitivity (CS) by the wire type IQI. Finally, the defect visibilities obtained with DDA were compared with those obtained with digitalized films.

4.1. Normalized Signal-to-Noise Ratio, SNRn. The normalized SNRn (see ASTM E 2597 for details) for the DDA system is a function of the number of integrated image frames during the exposure time. This is a basic difference to film exposures with their limited density range of $2.3<\mathrm{D}<4.2$ and a fixed exposure time resulting from the film sensitivity (ISO film speed) of the selected film system class and the density requirements.

DDA allow varying the SNRn by the overall image integration time in the computer in a much wider range, the maximum achievable SNRn is limited only by the quality of detector calibration. In Figure 5 curves of SNRn are shown as function of the integration time in different points.

The normalized SNRn measurement was made on the base material near to the wire IQI. The ROI (Region of Interest) size for calculation of SNRn was $20 \times 55$ pixels, 1100 points. 


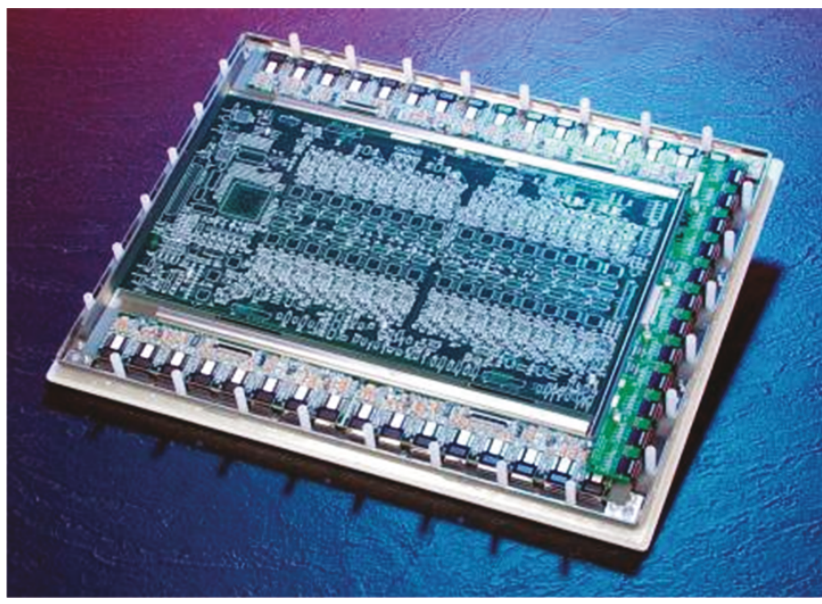

(a) Photo of DDA from backside

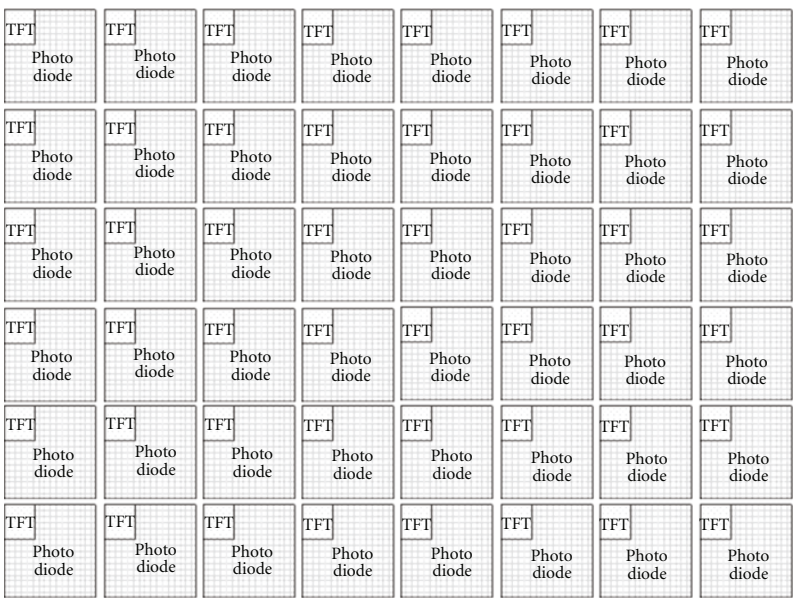

(b) Scheme of light sensitive detector matrix

FIgURE 3: Digital Detector Array-DDA.

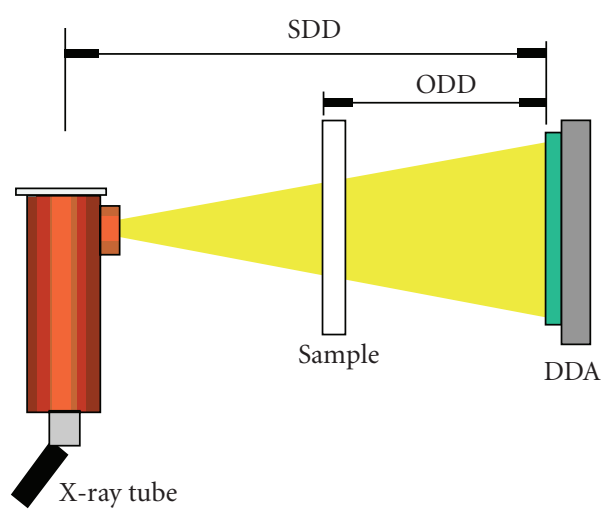

(a)

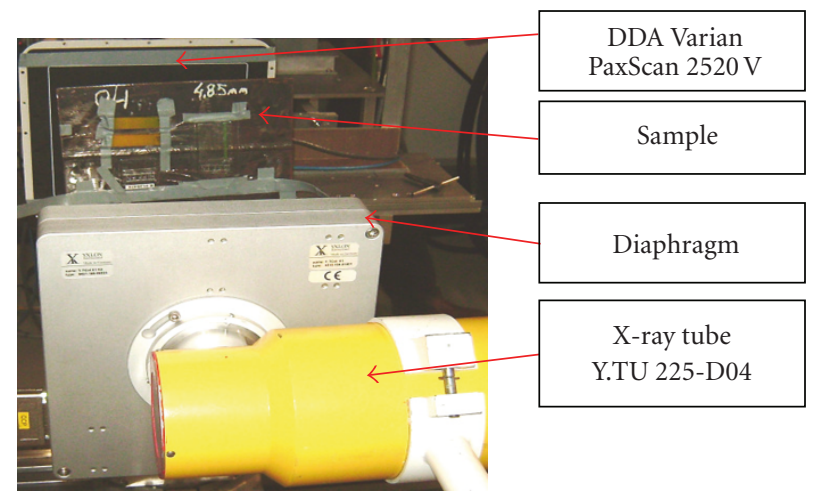

(b)

Figure 4: Arrangement: (a) Basic scheme, (b) Detailed view [9].

For short exposure times the SNRn is proportional to the square root of the exposure time (number of integrated frames) because of the SNRn limitation by quantum noise generated by the X-ray photons $[10,12]$. With longer exposure time the noise in the calibration data limits the achievable SNRn in the integrated image. Therefore it is necessary to use at minimum a double number of frames for the detector calibration as later during the real image acquisition of the inspected samples. The dependence of SNRn and wire perceptibility at $32,3 \mathrm{~mm}$ steel and $225 \mathrm{kV}$, $8 \mathrm{~mA}$ tube settings and a geometric setup of $700 \mathrm{~mm}$ $\mathrm{SDD} / 80 \mathrm{~mm}$ ODD in the central region of the sample is shown in Figure 6. The integration time was varied between $1 \mathrm{~s}$ and $512 \mathrm{~s}$ (with $1 \mathrm{~s}$ frame time), the gain calibration was done with 250 s integration time and 32,3 mm steel, the offset image with $500 \mathrm{~s}$.

4.2. SRb and Contrast IQI. In Figures 7 and 8 the performance of digital radiography is shown in terms of contrast sensitivity (single wire IQI read-out) as function of integration time of $1,2,4,8,16$ and 32 seconds. The requirements of ISO/DIS, using the compensation principle as indicated, is shown as blue line. Figure 7 shows that the minimum requirements of ISO/DIS 10893-7 can be reached with a minimum integration time of $4 \mathrm{~s}$ (W18, diameter $63 \mu \mathrm{m}$ ), $2 \mathrm{~s}$ (W17, diameter $80 \mu \mathrm{m}$ ) and $1 \mathrm{~s}$ (W15, diameter $130 \mu \mathrm{m}$ ) for the wall thickness of $4,9 \mathrm{~mm}$ to $9,7 \mathrm{~mm}$ [10].

In addition, the recognized single wire IQI is given for all exposure times. The single wire number W11, is recognized for SNRn values above 100, as required by ISO/DIS 108937 , the maximum contrast sensitivity reachable with this calibration is W14.

In Figure 8 it is possible to see that the requested sensitivities were obtained with an integration time of $1 \mathrm{~s}$ (W14, diameter $160 \mu \mathrm{m}$ ), $2 \mathrm{~s}$ (W12, diameter $250 \mu \mathrm{m}$ ) and $4 \mathrm{~s}$ (W11, diameter $320 \mu \mathrm{m}$ ) for the wall thickness of $19,2 \mathrm{~mm}$, $25,3 \mathrm{~mm}$ or $32,3 \mathrm{~mm}$, respectively [10].

For the integration time of $32 \mathrm{~s}$ wire sensitivities were obtained: W19 for a wall thickness of $4,9 \mathrm{~mm}$ and $6,4 \mathrm{~mm}$, W18 for a wall thickness of $9,7 \mathrm{~mm}$, W16 (wire diameter $100 \mu \mathrm{m})$ and W15 for a wall thickness of $19,2 \mathrm{~mm}$, W14 


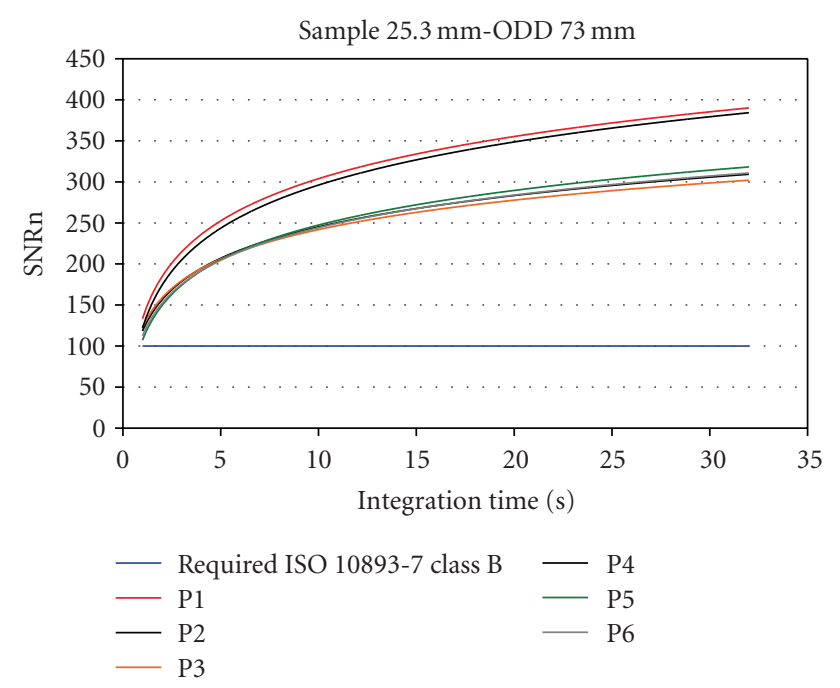

FIGURE 5: SNRn for WT 25,3 mm, image quality class B.

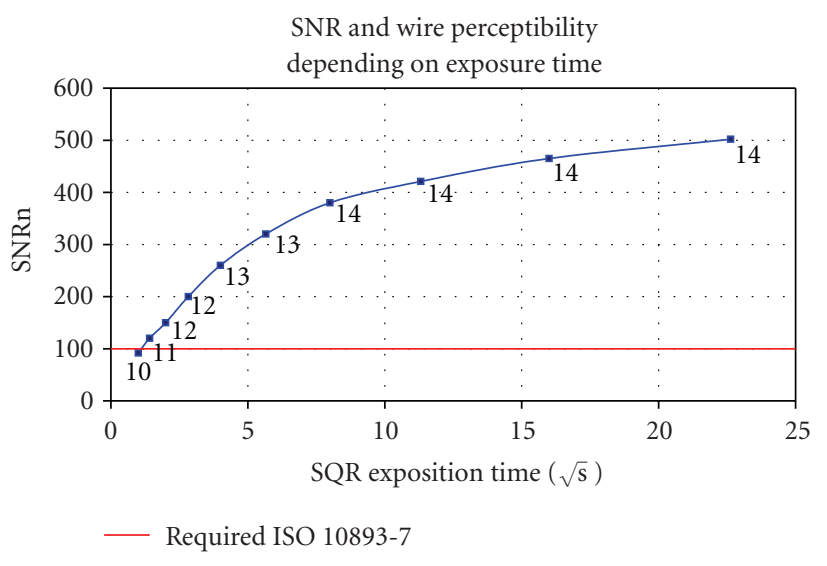

FIGURE 6: SNRn and wire perceptibility [10].

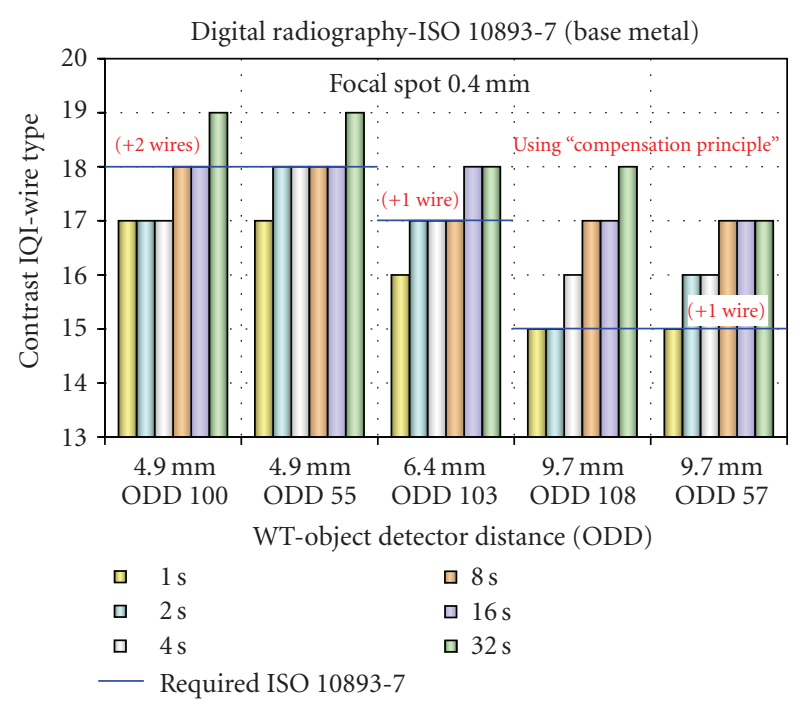

FIGURE 7: IQI wire sensibility—4,9 $\mathrm{mm}$ to $9,7 \mathrm{~mm}$.

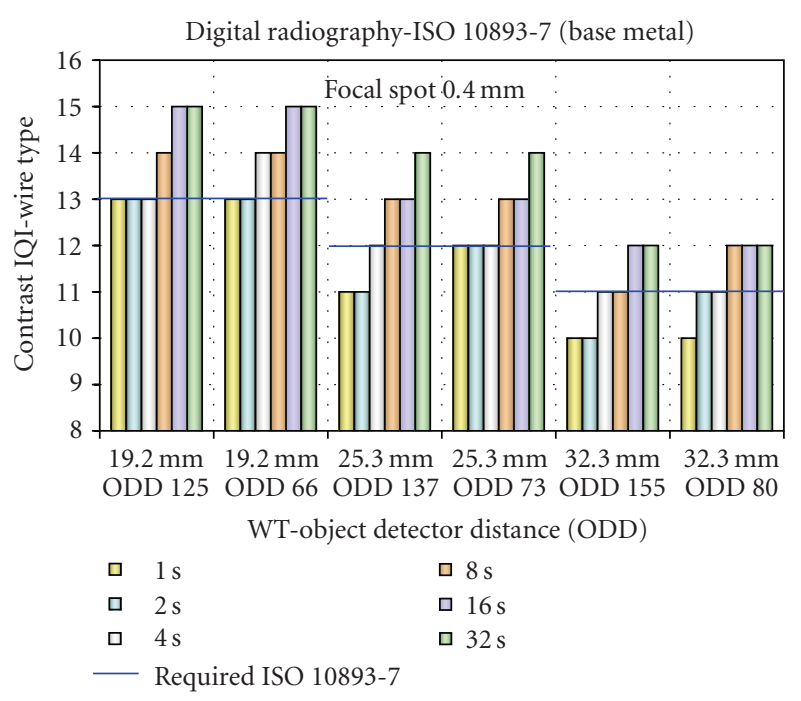

FIgURE 8: IQI wire sensibility-19,2 $\mathrm{mm}$ to $32,3 \mathrm{~mm}$.

for a wall thickness of $25,3 \mathrm{~mm}$ and W13 (wire diameter of $200 \mu \mathrm{m}$ ) for a wall thickness of $32,3 \mathrm{~mm}$. All these sensitivities are 2 wires higher than requested by ISO/DIS 10893-7.

4.3. Defects Visibilities. In this section comparisons are made between radiographic images obtained from digitalized films and the corresponding image from digital radiography using the DDA. The critical defects shown in the welds were artificially generated during the welding process for the purpose of comparison of indications.

The images shown in Figures 9 and 10 were generated with the program "ISee!" and were displayed in negative mode (like film). They are results of high-pass filtering using the filter "Enhance Detail" in "ISee!" [6].

This special 2D-FFT filter did not require any adjustable parameter and is optimized for optimum presentation of welds on 8 bit displays with only very weak filter artifacts [10]. At none of the shown examples the reduced total image unsharpness of the DDA system limits the visibility of fine indication details when compared to the film images. Quite contrary, the detail visibility with DDA is even improved by the limitation of high-frequency image noise as observed on the digitized film images. The minimum time indicated was the specific integration time that fulfilled the defects visibilities compared with film.

Figure 9 shows a performance comparison for a base metal wall thickness of 4,9 mm: (a) digitized AGFA D4 film (b) and (c) digital radiography with $1 \mathrm{~s}$ and $32 \mathrm{~s}$ integration time. In terms of defects visibility, they are better. In this case of $4,9 \mathrm{~mm}$ wall thickness the requirements of ISO/DIS for a minimum SNRn $>100$ for class B was fulfilled already with an integration time of $1 \mathrm{~s}$ and the IQI requirement was fulfilled with $4 \mathrm{~s}$ integration time.

In Figure 10 the performance of digital radiography is compared, for a wall thickness of $25,3 \mathrm{~mm}$, base metal. The DDA with $1 \mathrm{~s}(\mathrm{~b})$ and $32 \mathrm{~s}(\mathrm{c})$ integration time is shown in 

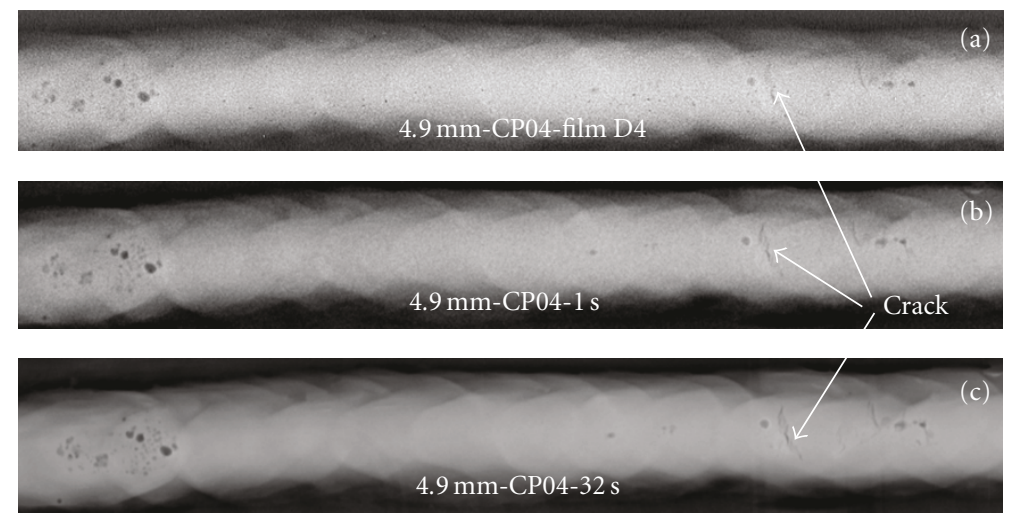

Figure 9: WT of 4,9 mm: (a) Film D4, DDA with (b) $1 \mathrm{~s}$ and (c) $32 \mathrm{~s}$ of integration time.
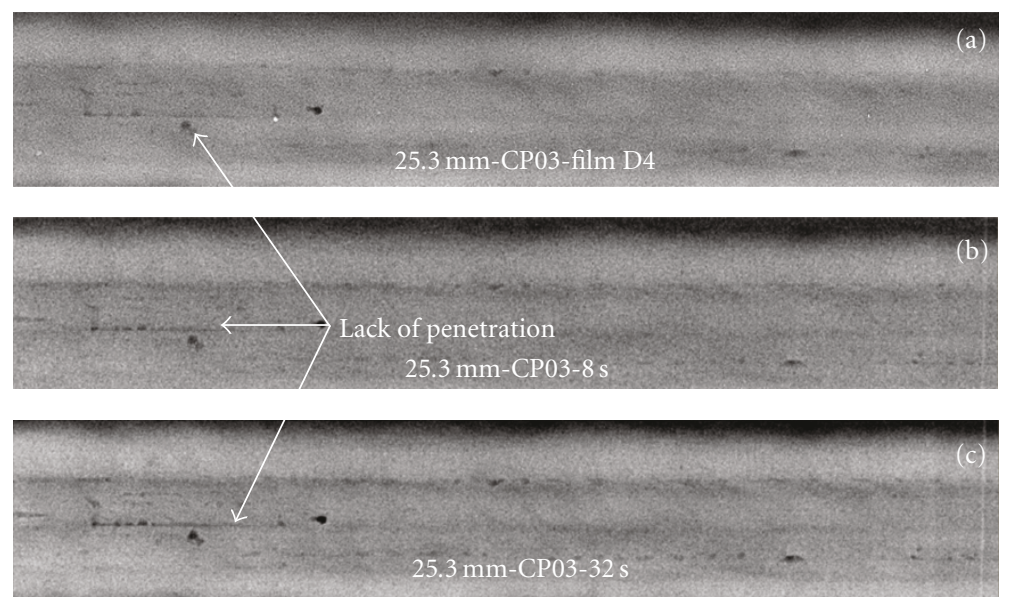

FIGURE 10: WT of 25,3 mm: (a) Film D4, DDA with (b) $8 \mathrm{~s}$ and (c) $32 \mathrm{~s}$ of integration time.

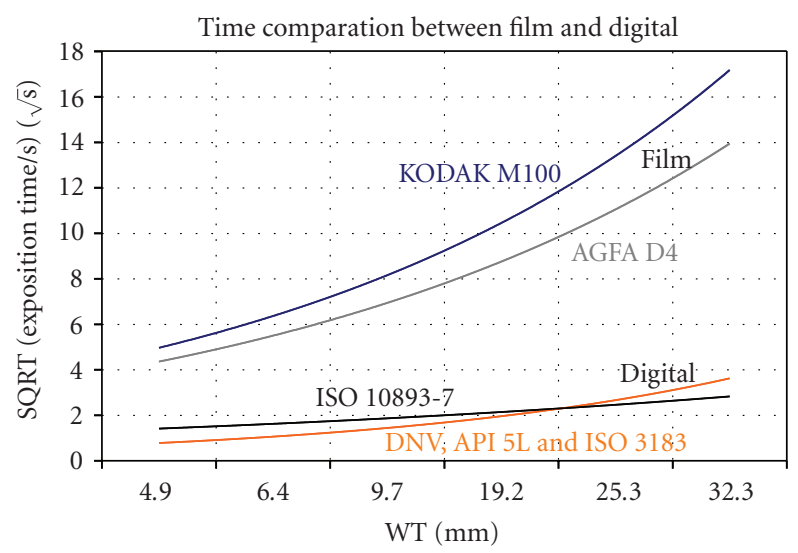

FIGURE 11: Film KODAK M100 and AGFA D4 in comparison with DDA.

comparison to the AGFA D4 film (a) in terms of defects visibilities. Independent of the noise, it is possible to see better details on the digital radiographs (b) and (c) than in the film (a). In this case of $25,3 \mathrm{~mm}$ wall thickness, the requirement of ISO/DIS 10893-7 for a minimum SNRn >
100 for class B was fulfilled with an integration time of $8 \mathrm{~s}$, and the IQI requirement was fulfilled with $4 \mathrm{~s}$ integration time, as reported previously.

\section{Integration Time of DDA Versus Exposure Time of Films}

The integration time of digital radiography and the exposure time of conventional film technique using 2 different films were compared in Figure 11. The advantage of reduced inspection time of DDA compared to films is clearly shown in the complete wall thickness range tested. It is important to note that the integration times used for the digital technique are very small in comparison with the practicable exposure times used with traditional films, while fulfilling all requirements of the investigated standards. For Kodak M100 film, Class 1 , for the wall thickness of $4,9 \mathrm{~mm}$ this variation is 7 times and for the rest of wall thickness the variation is between 22 to 40 times.

For AGFA D4 film, Class 1, for the wall thickness of $4,9 \mathrm{~mm}$ this variation is 5 times and for the rest of wall thickness the variation is between 15 to 28 times. 


\section{Conclusions}

Based on the above results, it can be concluded that the direct digital radiographic technique using DDAs is more sensitive than the conventional film technique, both in terms of visible wires of the Image Quality Indicators and in the detection of small real defects in the welds [13].

Hence, as foreseen in the purposed ISO/DIS 10893-7, digital radiography using DDAs can be employed directly on the productionlines of oil and gas pipelines, with important advantages over the conventional technique.

This digital technique therefore represents an advance in the quality of radiographic testing currently employed, in addition to its high degree of automation, which will allow for improved productivity and greater environmental friendliness.

\section{Acknowledgments}

The authors are indebted to the company XYLON International for carrying out the tests, as well as the staff responsible for the Post-graduation's program at the UNESP, Universidade Estadual Paulista-FEG. The authors would also like to thank TenarisConfab for its support in terms of technical and financial resources, which enabled this paper to be carried out.

\section{References}

[1] L. Pick and O. Kleinberger, "Technical highlights of digital radiography for NDT," Materials Evaluation, vol. 67, no. 10, pp. 1111-1116, 2009.

[2] E. V. Moreira, H. R. Simões, J. M. B. Rabello, J. R. De Camargo, and M. Dos Santos Pereira, "Digital radiography to inspect weld seams of pipelines—better sensitivity," Soldagem e Inspecao, vol. 13, no. 3, pp. 227-236, 2008.

[3] ISO/DIS 10893-7, "Non-destructive testing of steel tubespart 7: digital radiographic testing of the weld seam of welded steel tubes for the detection of imperfections," Geneva, Switzerland, 2009.

[4] A. G. Farman, C. M. Levato, D. Gane, and W. C. Scarfe, "In practice: how going digital will affect the dental office," Journal of the American Dental Association, vol. 139, 2008.

[5] R. Pincu and O. Kleinberger, "Portable X-ray in the service of art," Materials Evaluation, vol. 68, no. 3, pp. 311-318, 2010.

[6] U. Ewert, U. Zscherpel, C. Bellon, G. R. Jaenish, J. Beckmann, and M. Jechow, "Flaw size dependent contrast reduction and additional unsharpness by scattered radiation in radiography-film and digital detectors in comparison," in Proceedings of the 17th World Conference on Non-Destructive Testing, Shanghai, China, 2008.

[7] API 5L, Specification for Line Pipe, American Petroleum Institute, Washington, DC, USA, 2007.

[8] ISO 3183, "Petroleum and natural gas industries—steel pipes for pipeline transportation systems," Geneva, Switzerland, 2007.

[9] E. Moreira, M. C. Fritz, H. R. Simoes, J. M. B. Rabello, and J. R. Camargo, "Flat-panel detectors are accepted for digital radiography in place of conventional radiography in pipeline weld inspection," in Proceedings of the 4th Conferencia Panamericana de END, Buenos Aires, Argentina, 2007.
[10] E. Moreira, R. Lopes, M. Pereira, J. M. B. Rabello, U. Zscherpel, and D. Oliveira, "Real application stage of DR in weld seam of pipes for gas and oil linepipes," in 10a COTeq, Conferência de Tecnologia, Salvador, Brasil, 2009.

[11] U. Ewert, K. Bavendiek, J. Robbins, et al., "New compensation principles for enhanced image quality in industrial radiology with digital detector arrays," Materials Evaluation, vol. 68, no. 2, pp. 163-168, 2010.

[12] D. F. Oliveira, Análise da Radiografia Computadorizada em Condições de Águas Profundas, Dissertação (Mestrado em Engenharia Nuclear), COPPE-Universidade Federal do Rio de Janeiro, Rio de Janeiro, Brazil, 2007.

[13] U. Zscherpel and K. Bavendiek, "High quality radiography with digital detector arrays," in Digital Imaging VIII Conference, Foxwoods, Conn, USA, 2005. 